\title{
Changes in Surgical Conduct Due to the Results of Intraoperative Transesophageal Echocardiography
}

(Rev Bras Anestesiol 2010;60:2:192-197)

To the Editor,

It was with great interest that I read the case report published by Revista Brasileira de Anestesiologia on the change on surgical conduct due to the results of intraoperative transesophageal echocardiography. I would like to congratulate the authors and make a few considerations.

Hemodynamic evaluation using echocardiography that allows an estimate of several important parameters for decision making in the perioperative period is one of the main benefits of this method. The ultrasound gives us an estimate of: cardiac output, intracavitary pressure gradients, valvular area, volumes and regurgitation fractions, pulmonary-systemic (Qp/Qs) flow relationship, and to estimate pulmonary and intracavitary arterial pressures. Many of those variables show good relationship when compared to more invasive methods 1. Echocardiographic hemodynamic analysis of patients with congenital cardiopathy requires care when interpreting the data. In the absence of pulmonary stenosis, the peak pressure of the left ventricle is equivalent to the systolic pressure in the pulmonary artery (SPPA) ${ }^{2}$. In the case reported, the authors estimated a SPPA of approximately $80 \mathrm{mmHg}$ obtained through the simplified Bernoulli equation $\left(4 \mathrm{~V}_{\mathrm{PEAK}}{ }^{2}\right)$ by using the peak velocity of the regurgitant tricuspid flow. However, in this clinical case, this pressure does not reflect the true systolic pressure in the pulmonary artery, but only the right ventricular systolic pressure (RVSP). In the presence of significant pulmonary stenosis (subvalvular, valvular, or supravalvular), the RVSP is a reflection of the force of the right ventricle to overcome the pressure gradient in the obstructed area. For the correct calculation of the SSPA in patients with pulmonary obstruction, we should subtract the maximal pressure gradient of the pulmonary stenosis from the right ventricular systolic pressure ${ }^{3}$.

SSPA $=$ RVSP - maximal pressure gradient of the pulmonary stenosis

The pressure gradient of the pulmonary stenosis could be obtained by using continuous Doppler over the stenotic area and placing the peak velocity in this area in the modified Bernoulli equation. To obtain a correct alignment of the ultrasound beam with the pulmonary blood flow, the best views in the transesophageal US to evaluate the RV outlet at the level of the esophagus are achieved by the following cuts: transversal axis of the aortic arch in the upper esophagus between $60^{\circ}$ and $90^{\circ}$ (Figure 1), transversal axis of the aorta in mid esophagus between $0^{\circ}$ and $20^{\circ}$ (Figure 2), transgastric longitudinal view of the RV between $90^{\circ}$ and $120^{\circ}$ (Figure 3), and deep longitudinal transgastric view of the RV between $0^{\circ}$ and $20^{\circ}$ with rotation of the probe to the right in an attempt to localize the RV outlet and pulmonary valve.
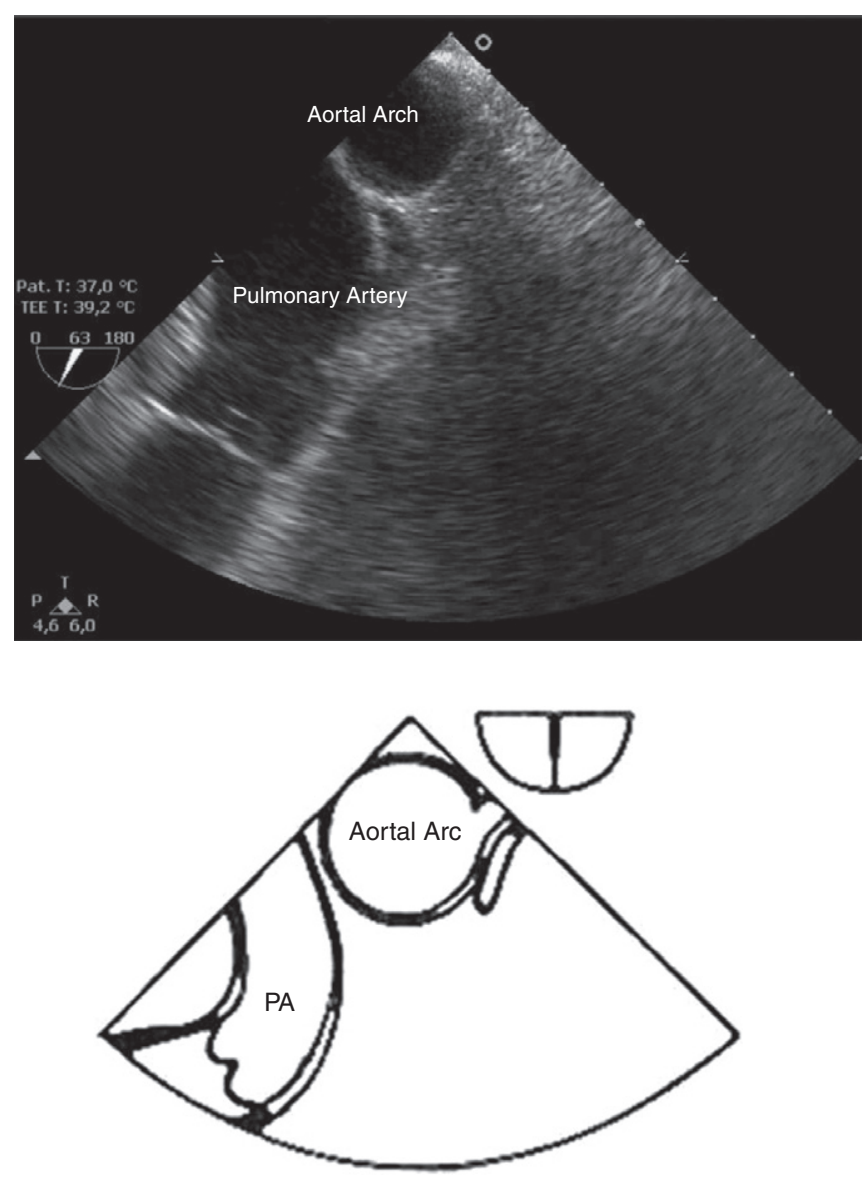

Figure 1 


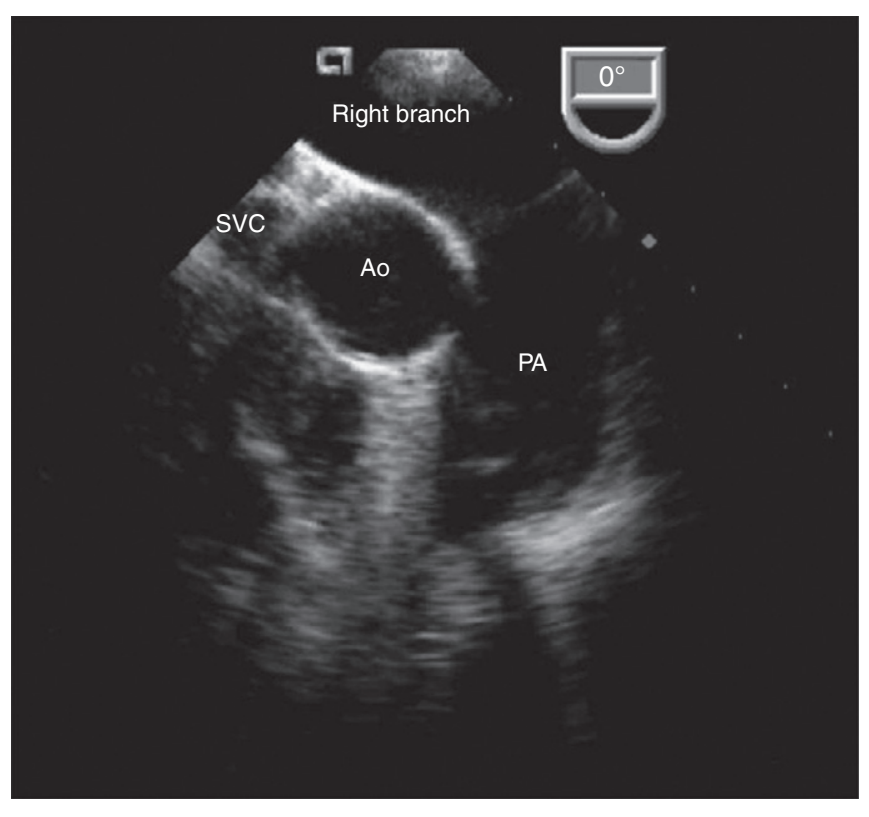

Figure 2

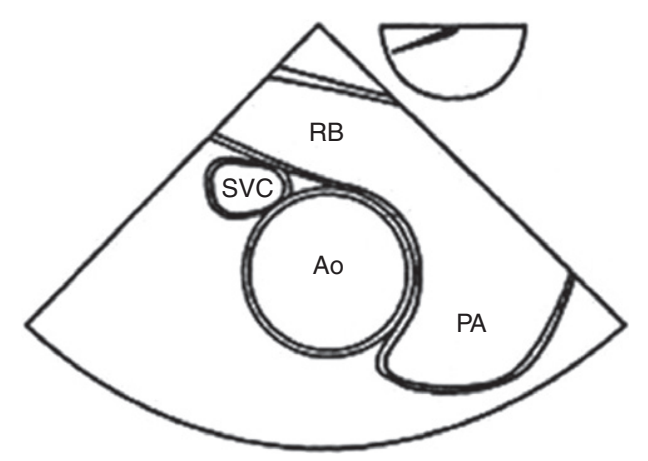

Subtracting the pressure gradient between the left and right ventricles from the systolic blood pressure is another alternative to calculate the RVSP in patients with interventricular communication (IVC). In the presence of aortic stenosis or left ventricular outlet obstruction, this formula is useless.

RVSP = systolic arterial pressure - systolic gradient of the IVC $\mathrm{RVSP}=$ systolic BP -4 (peak velocity divided by the IVC) ${ }^{2}$
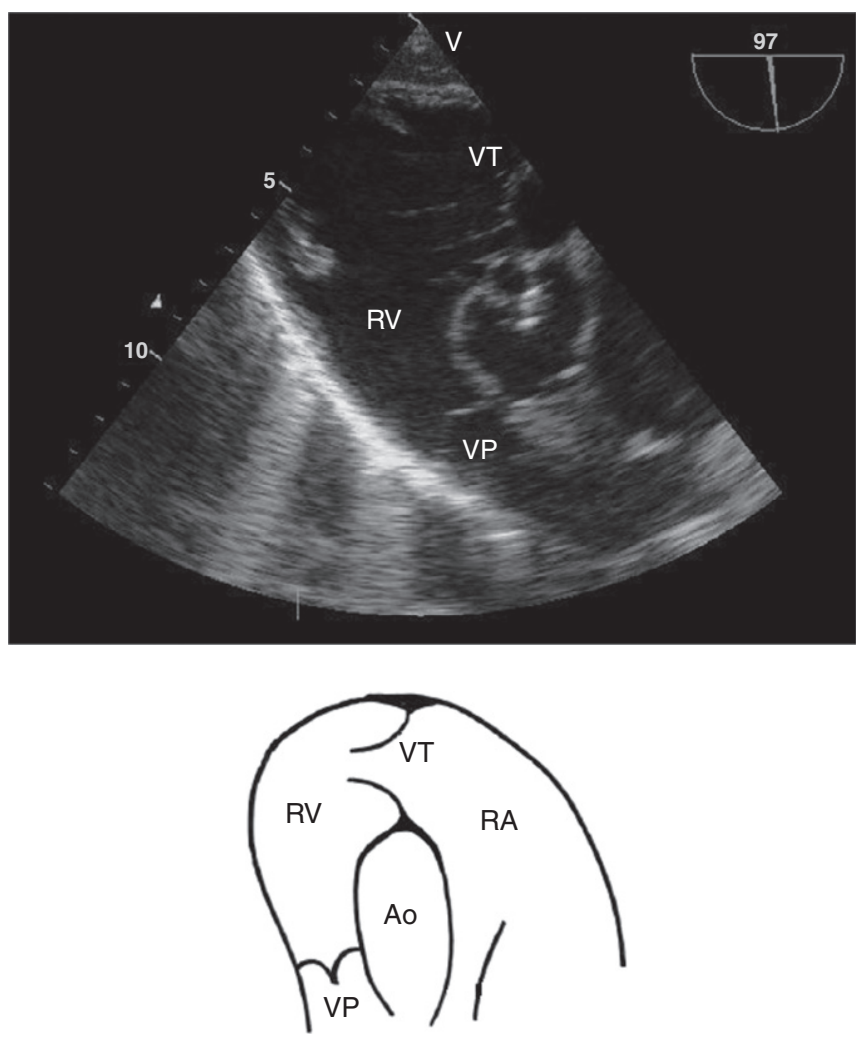

Figure 3

I would also like this opportunity to praise the efforts of the authors to report the benefits of intraoperative transesophageal echocardiography, a technique seldom used among us that brings enormous benefits to the management of patients with cardiopathies undergoing cardiac and/or non-cardiac surgery. At the Instituto Nacional de Cardiologia, we have used this method routinely since 2004 and recently implemented the intraoperative echocardiography department.

Sincerely,

Carlos Galhardo Júnior, TSA

Coordinator of the Adult Anesthesiology Department Instituto Nacional de Cardiologia - INC/MS 


\section{REFERÊNCIAS / REFERENCES}

01. Currie PJ, Seward JB, Chan KL et al. - Continuous wave Doppler determination of right ventricular pressure: a simultaneous Doppler-catheterization study in 127 patients. J Am Coll Cardiol, 1985;6:750-756.

02. Quiñones MA, Otto CM, Stoddard M et al. - Recommendations for quantification of Doppler echocardiography: a report from the Doppler Quantification Task Force of the Nomenclature and Standards
Committee of the American Society of Echocardiography. J Am Soc Echocardiogr, 2002;15:167-184.

03. Ahmed SN, Syed FA, Porembka DT et al. - Echocardiographic evaluation of hemodynamic parameters. Crit Care Med, 2007;35(Suppl):s323-s329.

04. SILVA, SILVA, SEGURADO, KIMACHI, SIMÕES - Mudança de Conduta Cirúrgica Motivada pela Ecocardiografia Transesofágica Intraoperatória. Rev Bras Anestesiol, 2010;60:192-197. 